\title{
Lo imaginario social en el mundo digital. Apuntes sobre dos investigaciones acerca de las Nuevas Tecnologías e Internet
}

\author{
Luis Alfonso Chávarro \\ Universidad del Valle, Cali, Colombia \\ lchavarro26@gmail.com
}

\begin{abstract}
RESUMEN
Partiendo de la consideración de lo imaginario y de las concepciones claves para operativizar conceptos como significación social, institución y funciones, señaladas por Castoriadis, este artículo destaca el trabajo de Daniel H. Cabrera para entender lo imaginario de las nuevas tecnologías, así como el trabajo de Patrick Flichy sobre lo imaginario de Internet, fundamentado en las nociones de ideología y utopía de Ricoeur. Tanto las nuevas tecnologías digitales como la red Internet constituyen el complemento idóneo característico de lo que se suele llamar la sociedad de la información desde cierto determinismo tecnológico. El examen de estos sendos trabajos de lo imaginario en tiempos de la globalización por vía de la tecnología constituyen un baluarte del pensamiento crítico que permite entender por qué en este nuevo siglo la democracia parece retroceder a las formas decimonónicas dado que se ha convertido en premisa pensar la vida sin requerimiento del Estado, sumidos en un individualismo conectado y de opinión pública virtual que parece estar aún lejos de lo que significó, para la democracia griega, el ágora pública.
\end{abstract}

Palabras clave: Imaginario, significaciones sociales, ideología, nuevas tecnologías, Estado, democracia.

\section{The social imaginary in the digital world. Notes on two investigations about New Technologies \& Internet}

\begin{abstract}
Starting from the consideration of the imaginary and the key conceptions so that concepts such as social significance, institution and functions are put into effect, as indicated by Castoriadis, this article highlights the work of Daniel H. Cabrera to understand the imaginary of new technologies, as well as Patrick Flichy's work on the imaginary of the Internet, based on Ricoeur's notions of ideology and utopia. Both the new digital technologies and the Internet are the ideal complement characteristic of what is usually called the information society from the point of view of the technological determinism. The examination of these two works of the imaginary in times of globalization through technology is a defense of critical thinking that allows us to understand why in this new century democracy seems to go back to the nineteenth century forms since it has become premise to think of a life without the requirement of the State, submerged in a connected individualism and virtual public opinion that seems to be still far from what the public agora meant for Greek democracy.
\end{abstract}

KeYwords: Imaginary, social meanings, ideology, new technologies, State, democracy. 


\section{Bases conceptuales sobre lo imaginario}

\section{Introducción}

Los estudios sobre lo imaginario suelen asociarse, y con razón, a trabajos sobre las representaciones, en el campo de la psicología social, o a investigaciones sobre las mentalidades, en el campo de la historia. También, a los análisis de los mitos en antropología y al estudio de arquetipos en psicoanálisis. Obviamente, con todo ello tienen que ver dado que son categorías de investigación de lo simbólico, sólo que según las disciplina, lo simbólico adquiere su matiz.

Como se ha afirmado en otro lugar (Chávarro, 2012, p. 17), de acuerdo con Moscovici las representaciones son esquemas mentales resultado de la socialización de la ciencia en la modernidad que determinan la visión de la realidad en los individuos y grupos (Moscovici, cit. Mora, 2002, p. 7). A su vez, los historiadores han trabajado la noción de mentalidad (Le Goff, 1990, p. 263) como una visión del mundo o conjunto de representaciones o actitudes mentales propias de una época. En antropología, los estudios de lo imaginario se emparentan con el trabajo acerca de lo que Durkheim denominara representaciones colectivas como los mitos y la religión (Durkheim, 2000, p. 35), y, en conjunción con ciertas tendencias del psicoanálisis, el análisis de los mitos ha dado para hablar de arquetipos y todo un enfoque de análisis del imaginario cultural denominado mitoanálisis y mitocrítica (Durand, 2005). Es precisamente en la obra de Freud, con sus ideas de inconsciente y deseo, en la que confluyen las tesis sobre la configuración del orden simbólico y la distinción entre lo real y lo imaginario. (Castoriadis, 1993)

\section{Nociones básicas para entender lo imaginario}

Retomando los notables alcances de las tesis del crítico y continuador del psicoanálisis, el filósofo griego Cornelius Castoriadis, Daniel H. Cabrera elabora una gran fundamentación para su obra, un trabajo destacado sobre lo imaginario en la tecnología (Cabrera, 2006). Allí se parte de que, para discurrir sobre lo imaginario, se precisa examinar la raíz de donde proviene el término, hoy convertido en sustantivo: ya como derivación de imaginación o asociado con imagen y fantasía.

En razón de lo anterior, se entiende por imaginación la capacidad humana para producir representaciones de la realidad a través de procesos como la percepción y la memoria, pero también de la creación. En otras palabras, en la imaginación se implican tanto la facultad de producir imágenes o copias de la realidad, que se reproducen por el filtro de arquetipos o simbolizaciones previas, como también fantasías que anticipan lo no existente y se traducen en invenciones y creaciones que no tienen relación directa 
con la realidad. Imaginar significa aprehender la realidad, pero también trascenderla, y de esa manera se cumple tanto la función de realidad para orientarse en lo existente, como la función de irrealidad, es decir, la capacidad de sońar, de estetizar, de explorar alternativas a la realidad existente.

Con base en la distinción de estas nociones, lo imaginario deriva de la capacidad de imaginación tanto individual como social, en un proceso reproductivo de representaciones e imágenes, pero también creador de posibilidades. Es en este punto donde muestra sus bondades la teoría de lo imaginario, retomada de la obra de Castoriadis, en el paso de lo individual a lo social. Ello se puede entender con las concepciones, introducidas por Castoriadis, en su Institución imaginaria de la sociedad. (Castoriadis, 1993)

\section{Concepciones claves: significación social, institución y funciones}

En los términos de Castoriadis, la imaginación está ligada a la potencialidad del deseo. En su perspectiva, de acuerdo con lo señalado por Angel Carretero, lo imaginario es:

[...] el resultado del despliegue de una fantasía que intenta restaurar una identidad originaria del sujeto, caracterizado por una originaria indistinción de sujeto y mundo, que había sido fracturada como consecuencia de las pautas institucionalizadas de socialización que le habían conferido una identidad racional. (Carretero Pasín, 2003, p. 95)

En términos analíticos, la imaginación primera o radical se entiende como la capacidad de ver la ausencia, de trascender la fractura que imprime lo real con el deseo, y en ello estaría la anticipación creativa y la capacidad de transformación. Con la imaginación segunda, la traducción de la realidad en copias o imágenes estaría en la base de la configuración de una visión de lo real, del mundo, determinada en gran parte por lo social dado que las representaciones e imágenes son prestadas del entorno social.

La institución de la sociedad radica en la socialización que experimenta el individuo, en la que las representaciones o imágenes de la realidad construida socialmente le son dadas como lentes para percibir, organizar y conceptuar la realidad. Con la institucionalización deviene el orden simbólico, el ingreso a una visión del mundo que determina lo que es real y lo que no lo es, pero que no se queda en una programación cultural sino que se modifica individual o colectivamente cuando la imaginación propicia nuevas visiones de la realidad. Así, el imaginario social deviene en lo que es pensable e imaginable en una sociedad y en una época. Como se advirtió antes, esta noción se parece bastante a la de mentalidad.

Un elemento clave para que se construya socialmente lo imaginable son las significaciones sociales, es decir, de acuerdo con Cabrera, las creencias compartidas constituidas por ideas, sentimientos e imágenes, las que a su vez, constituyen la matriz de 
significados aceptados e incuestionables (Cabrera, 2006, 25). Castoriadis introduce la noción de magma como la fuente original de la que manan indistintamente significaciones instituyentes que luego serán filtradas, depuradas por la socialización instituida (Castoriadis, 1993, p. 2). Las significaciones sociales cumplen las funciones de instituir un orden social, justificarlo para alcanzar su legitimación o preservar la identidad a través de la integración o el consenso; pero, también, cuestionarlo, de manera reflexiva y autónoma, para transformarlo. De acuerdo a la función que cumplan, las significaciones sociales se pueden traducir en ideologías, utopías, escatologías, etc.

\section{Una teoría de lo imaginario social}

En la perspectiva de Castoriadis, lo imaginario social es «[...] es lo que permite a una sociedad verse, imaginarse, definirse como un 'nosotros' concreto y particular y ver, imaginar y definir el mundo como su mundo (Castoriadis citado en Cabrera, 2006, p. 56). Su teoría de lo imaginario plantea una distinción entre imaginario individual y social, y para ambos polos destaca una dimensión primera o radical y una dimensión segunda. En sus propios términos, la dimensión radical es «[...] una facultad espontánea de representación que no está sujeta a un fin predeterminado» (Castoriadis, cit. Cabrera, 60), es decir, una forma de trascender lo especular o reflejo, y dar forma a lo que no está presente, la autonomía de la imaginación y su desfuncionalización. A diferencia de Freud, Castoriadis alude a que esta desfuncionalización de los imaginarios no sólo reside en el inconsciente, dado que no es sólo reflejo, sino que también aparece en la conciencia y la lógica, en un magma indiferenciado (Cabrera, 2006, pp. 60-61). El imaginario segundo consistirá en las representaciones que copian la realidad a través de la percepción y la memoria, y permiten entrar en lo instituido como realidad.

Asimismo, el imaginario social también posee las dos dimensiones, la radical y la segunda. Aquí es clave recordar que Castoriadis lo llama social porque deriva de la sociedad, a la que define como «[...] un magma de significaciones imaginarias sociales que dan sentido a la vida colectiva e individual» (Cabrera, 2006, p. 58) La sociedad, entonces, aparece con la socialización, es decir, un proceso de institucionalización y estructuración de la psiquis mediante el cual la sociedad no sólo impone pautas o represión sino que se da sentido a sí misma. El individuo se constituye como un fragmento itinerante de la sociedad y éste a su vez retoma de la sociedad las significaciones primarias desde las cuales resignificará el mundo. En dicha resignificación se crea la posibilidad de la autonomía individual y social, y no sólo la copia o programación. Se puede tomar distancia de lo instituido mediante la reflexión y queda la posibilidad de cambio, la autonomía.

Las disciplinas sociales estudian lo imaginario básicamente en su dimensión segunda, como lo instituido. A diferencia del magma instituyente en el individuo, constitui- 
do por representaciones, el magma instituyente social está constituido por representaciones complejas o significaciones sociales imaginarias. Estas significaciones tienen la característica de ser inmotivadas y efectivas; en el primer caso, son inmotivadas dada la imposibilidad de clasificar una sociedad de «falsa», y son efectivas, porque condicionan la acción y su interpretación (Cabrera, 2006, p. 60). Lo anterior no quiere decir que la visión del mundo fruto de la institución de la sociedad esté absolutamente determinada, pero tampoco cabe decir lo contrario, que todo sea indeterminado (Cabrera, 2006, p. 61).

El papel de las significaciones sociales se puede entender cuando operan en las elecciones y el hacer de los individuos y la sociedad «como definitorios de una constelación de significados y fines en los cuales y desde los cuales se construye el mundo social como este mundo, mi mundo" (Cabrera, 2006, p.63). Las mismas determinaciones y necesidades están atravesadas por las significaciones, y éstas resultan irreductibles al determinismo social, económico o funcional. La creatividad social es posible con el imaginario radical, y las determinaciones sociales quedan reservadas para el imaginario segundo.

Con las anteriores premisas, el imaginario radical de una sociedad es el «estructurante originario» soporte de las articulaciones «de lo que importa o no» (Cabrera, 2006, p. 65). A su vez, el imaginario social «es el fundamento ilimitado e insondable en el cual descansa toda la sociedad dada», en fin, "el conjunto de esquemas organizadores que son condición de representabilidad de todo lo que una sociedad puede darse» (Cabrera, 2006, p. 65).

El imaginario social solo se puede entender teniendo en cuenta las dimensiones estructurantes, que, igualmente, cumplen las funciones de representación, intención y afecto: «[...] la primera es estructurar las representaciones del mundo en general, estructuras específicas y sin las cuales no puede haber ser humano»(Cabrera, 2006, p. 70). Respecto a la función de intención «[...] es designar finalidades de la acción imponiendo lo que hay que hacer y lo que no hay que hacer, lo que es bueno hacer y lo que no lo es» (Cabrera, 2006, pp 70-71) Y respecto a los afectos «[...] es establecer los tipos de afectos característicos de una sociedad»(Cabrera, 2006, p. 71). Estas dimensiones son indisociables y no pueden concebirse como unidades diferentes. La representación implica una puesta en imagen de lo percibido, la intención alude al empuje o apetito en dirección a un objeto, y el afecto implica el resultado o la actitud.

$\mathrm{La}$ incorporación de las significaciones imaginarias en una sociedad mediante los procesos de socialización deviene en un tipo antropológico (Cabrera, 2006, p. 71). Así, para el caso de la sociedad moderna, la institución de las significaciones centrales convertidas en visión de mundo radica en la pretendida dominación «racional» sobre la naturaleza, lo mismo que la autonomía individual y social. A la primera corresponde el capitalismo, y a la segunda el individualismo (o mejor el conformismo generalizado) (Cabrera, 2006, p. 71). 
En síntesis, las significaciones sociales constituyen creencias o verdades prácticas que orientan la acción de los individuos y que, de su estructuración, pueden dar lugar a tipos funcionales de lo imaginario social segundo como las ideologías, las representaciones sociales, las utopías, etc. Las funciones de las significaciones sociales, centrales en el imaginario social, pueden oscilar entre la deformación de la realidad, la justificación del poder, la preservación de la identidad, y en ello adquieren ya sea la forma de ideologías, representaciones sociales, utopías y demás.

\section{Esbozos de un método}

Para analizar lo imaginario social, las unidades de análisis son palabras o acciones, en las que se descubre las representaciones, las intenciones y los afectos de las significaciones sociales. De esta manera, su análisis implica trabajar los discursos y las instituciones.

Una investigación sobre lo imaginario, como la emprendida por Cabrera en el caso de las «nuevas tecnologías» como significaciones sociales, trata de dar cuenta de las significaciones puestas en juego por la industria o el mercado, inscritas en el imaginario que las produce, resignificando, produciendo nuevas nociones y jugando su papel en la articulación de la experiencia social aun siendo resultado de una deformación o como fuente de legitimación, integración e identidad colectiva (Cabrera, 2006, p. 71).

En investigaciones empíricas como la mencionada, lo imaginario se puede analizar desde las significaciones sociales del imaginario segundo, en unidades de análisis como palabras y acciones que pueden ser entendidas como signos y discursos. Cabrera denomina discurso a un conjunto de enunciados de producción y recepción en un proceso de sentido. Entiende lo social en su dimensión significante constitutiva, y la significación siempre es social. En ese sentido, el análisis de los discursos llevaría a la comprensión de la institución social de la realidad, inscrita en la red discursiva donde aparecen las representaciones conectadas en su materialidad significante.

\section{La tecnología en lo imaginario}

\section{La técnica y la tecnología en lo imaginario de la modernidad}

Para iniciar la exposición de la tecnología en lo imaginario, hay que partir de considerarla como centro de representaciones, afectos y deseos colectivos. La tecnología ha estado en el centro de lo imaginario de la modernidad y de ello dan cuenta los discursos del progreso y el desarrollo. Es evidente que el término tecnología viene de dar desplazamientos semánticos, en particular, de la técnica hacia la ciencia aplicada. Lo cierto es que, en plena modernidad del siglo XIx, la tecnología se convierte en un verbo equiva- 
lente a la acción de introducir procedimientos técnicos y hacer más eficiente algo, hasta aparecer en los documentos políticos de la tecnocracia como signo de desarrollo.

La técnica deviene central en la modernidad dado que, de acuerdo con Ellul, constituye un hecho social: "Ningún hecho social humano, espiritual, tienen tanta importancia como el hecho técnico en el mundo moderno» (Ellul citado en Cabrera, 2006, p. 92). Es entonces lógico que se convierta en objeto de investigación en la perspectiva de lo imaginario dado que la técnica o tecnología tiene una dimensión significante, un conjunto de significaciones puestas en juego en y con los procesos estructurantes de la sociedad. Su sentido de lo social radica en que genera una fuente de discursos comerciales constantes en anuncios, promociones y comentarios para su distribución y consumo, pero también constituye un magma de lo imaginario social para sus creadores y promotores. Como conjunto de significación, se convierte en fuente de sentido para la sociedad y la historia, porque ingresa en la vida cotidiana y hace parte de las expectativas colectivas. En ese sentido, Cabrera afirma: «La técnica moderna recela que, tanto para la sociedad como para los individuos, se ponen en juego significados de lo histórico-social como matrices y modelos de lo que vale la pena ser vivido como valioso» (Cabrera, 2006, p. 108).

En una perspectiva de lo imaginario, la técnica solo puede ser entendida en relación a la idea de progreso (Nisbet, 2006). Desde el siglo XIX, en un entorno positivista y de desarrollo industrial, el cambio tecnológico se fue asociando a cambio social en el sentido del avance y progreso: «El futuro de la sociedad y del individuo se tornó deseable y realizable por el esfuerzo del presente técnico de la sociedad. Así, se hizo inteligible el tiempo social como historia» (Cabrera, 2006, p. 93). En esencia, en plena modernidad, las significaciones de su temporalidad están atravesadas por significaciones tecnológicas.

El papel de la técnica en la construcción de significaciones de una temporalidad social del progreso se puede entender si se mira la peculiar correlación del uso social de tres inventos tecnológicos en el siglo xix: el reloj, el ferrocarril y el telégrafo. El reloj, como máquina para medir el tiempo, en un contexto industrial permitió la sincronización de la acción de los hombres (Mumford, 1996) como una forma de racionalidad operante que permitió organizar las faenas industriales. No es por casualidad que fuera el primer artefacto de producción masiva. Usado para medir la duración de los viajes en el transporte hizo posible la existencia de las referencias temporales comunes. No hay que olvidar que el término watch (reloj) traducido normalmente en su forma verbal como mirar y observar, derivó en vigilar, es decir, mirar cómo usan el tiempo los hombres. Como máquina omnipresente, el reloj llegó a ser parte de las significaciones sociales como ordenador de la vida privada e individual. Se convirtió en el sonido mecánico al comenzar el día (referencia temporal) como despertador, lo mismo que como adminículo corporal con su versión de reloj de pulsera: «Este reloj marca el tiempo 
desde el lugar donde puede medirse el pulso corporal, recordando el pulso social en el que el individuo está inmerso» (Cabrera, 2006, p. 96).

Como lo ha expresado Attali (1982), con la máquina del tiempo, el reloj, nace el tiempo de la máquina. Es la época en que Benjamin Franklin expresa la frase que se convertirá en ley del capitalismo El tiempo es oro, y un poco después David Ricardo y Adam Smith calculan el valor de las cosas a partir del tiempo de trabajo. De allí a la organización de tiempos y movimientos de Frederick Taylor, y la cadena de montaje de Henry Ford, se tiene la expresión más avasalladora de la racionalidad mecánica, su significación social central y clave para la reproducción del capital. Hacia 1883, Greenwich es considerado el meridiano cero y el mundo es dividido en paralelos de latitud y longitud. La máquina ha devenido en medida del espacio geográfico, una dimensión espacio-temporal que será bien retratada la obra de Julio Verne La vuelta al mundo en ochenta dias.

Asimismo, la conexión que, con base en los postulados de Attali y Heller construye Cabrera, resulta clave para entender cómo las significaciones de la tecnología se traducen en temporalidad social, en representaciones del progreso. El tren hace posible el viaje como progreso lineal. En los viajes de ultramar, regresar era visto como una espera ansiosa. Con el ferrocarril, y con los desplazamientos migracionales del campo a la ciudad en busca del trabajo que ofrecían las nacientes industrias, el hecho de regresar es visto como un fracaso. El viaje se convierte en una forma de avance directo, de donde surge la metáfora del progreso lineal. El ferrocarril dispara la fantasía social: se debe avanzar hacia el futuro como lo hace la locomotora, y la misma historia adquiere la figura del tren, el tiempo social es un avance hacia el futuro. La relación reloj-ferrocarril-telégrafo permite la coordinación de los viajes. El tiempo en que pasa el ferrocarril se convierte en la hora de referencia, lo que a su vez conducirá a la unificación de la hora en el mundo a partir del meridiano Greenwich.

Por ser una significación social central de la modernidad, la técnica ha sido blanco favorito para interpretaciones desde las ciencias sociales que han puesto de presente el rol de su dimensión imaginaria. Jacques Ellul la relaciona con la mecanización del universo y como una fuerza con tendencia a la autonomía. En ello distingue características autonomizantes de la técnica como su automatismo orientado por lo más reciente y eficaz, la calificación de fuerza irreversible y ciega, y sobre todo, la indivisibilidad entre el artefacto y sus usos dado que no es una herramienta neutral. La técnica deviene en autónoma cuando el hombre se ve impedido de escoger su destino. En el mismo sentido, para otro gran pensador de la técnica como Lewis Mumford (Mumford, 1996), ésta ha marcado el tiempo social humano, y por ello él introduce las nociones de fase técnica y complejo tecnológico consistente en materiales, fuentes de energía y objetivos sociales en una época (Chávarro, 2008, p. 13). En consonancia con lo anterior, Cabrera retoma de Castoriadis la consideración de la técnica como una dimensión constitutiva 
de la sociedad. Los objetos técnicos no son neutros ya que desatan significaciones propias del hacer moderno, orientadas por las representaciones de la eficacia, con lo que la dimensión funcional y estructural de la técnica resulta indisociable de las dimensiones significativas.

Por ello, la técnica ha sido interpretada, en la tradición de la Escuela de Frankfurt, como algo más que la mera instrumentalidad material de los artefactos, como una forma de dominación social o ideología. En otro lugar se ha presentado la tesis de Herbert Marcuse de que la técnica es a la vez fuerza productiva e ideología (Marcuse, 1985). Para este autor, el progreso es un sistema de dominación y coordinación que hace contener el cambio social, y por ello, las formas predominantes de control social son tecnológicas incluido el fetichismo de los aparatos. La visión mecánica del mundo ha reemplazado la dependencia personal por el orden objetivo de las cosas, y con ello, la racionalidad instrumental ha llevado a la irracionalidad y lo que Weber denominara desencantamiento del mundo (Chávarro, 2008, p. 19). En la misma tradición de la Escuela de Frankfurt, Habermas (1980, p. 344) ha destacado que la comunicación es tan importante como la apropiación de la naturaleza que orienta la racionalidad operante llamada técnica. La intervención del Estado para financiar innovaciones ha hecho de la técnica una ciencia aplicada o tecnología, imperativo de avance para los tecnócratas que hace del progreso científico-tecnológico la fuente de legitimación del poder y. con ello, se erosionan los espacios públicos, lo que se traduce en despolitización de la sociedad.

En el mismo sentido, Castoriadis alude a la dimensión imaginaria afirmando que la técnica es aquello por lo cual cada sociedad se da a sí misma lo que para ella es realracional, destacando junto con Marx, que el control de esta razón operante puede hacer que la sociedad sea diferente. Agrega que la técnica no es solamente material sino racional puesto que está implicada en la organización de la sociedad. Sus significaciones imaginarias no son sólo ideología, en el sentido de Marcuse, sino también creación de lo social: «[...] es una nueva fuente de legitimación de la sociedad industrial, pero su fundamento no remite únicamente a la necesidad de legitimación de un sistema social sino al modo de ser de la sociedad como institución imaginaria» (Castoriadis citado en Cabrera, 2006, p. 76).

\section{La tecnología y lo imaginario del progreso}

La técnica ha existido siempre, pero en su versión moderna de tecnología difiere de toda técnica anterior en sentido y función social. La técnica entonces es una significación social central en el imaginario contemporáneo en las cuatro polaridades constitutivas: las imágenes y expectativas en relación a la temporalidad, y la ideología y utopía, en relación a la dimensión de la institucionalidad. Con relación a la significación social de temporalidad, se introduce la idea de progreso como deslizamiento de la técnica a la 
sociedad, es decir, que la mejora técnica significa progreso social, y por tanto la técnica se convierte en el símbolo de un futuro mejor (Cabrera, 2006, p. 116). En el siglo XIx, la fuerza de la idea de progreso reside en su capacidad de estimular la imaginación colectiva creando imágenes de una sociedad deseada. Pero el progreso no es una mera idea, es toda una creencia que adquiere ribetes de mito, toda una significación imaginaria social que da sentido a la acción social. A su vez, la fuerza del progreso no descansa en su carácter de verdad o falsedad, ni en su verosimilitud, sino en su capacidad de dotar de sentido el esfuerzo individual y social y su capacidad de imponer unos fines deseables para la acción social.

$\mathrm{Al}$ poner de presente la aceleración y la velocidad, la técnica crea una distancia entre experiencia y expectativa, por lo que el pasado se hace intrascendente y el futuro se espera con ansiedad, con-fundiendo mejor técnica y avance social y, resultado de ello, la expectativa propia del progreso. La fe en el progreso resulta de la fe en el crecimiento económico, prueba por experiencia de que la eficacia de las innovaciones tecnológicas, surte efecto en la realidad. La experiencia del avance tecnológico y las expectativas de tiempos mejores confluyen entonces en una creencia: la fe en el progreso (Nisbet, 1996). El programa positivista de la ciencia creará un modelo de temporalidad social en la que la sociedad industrial es la etapa más avanzada del tren de la historia. Estas significaciones sociales moldearon lo imaginario del siglo xIx. De ellas participaron los industriales, sońados por Saint Simon con su Catecismo de los industriales, los científicos positivistas de Comte, y los obreros, portadores de la esperanza, de Marx. Sólo los ludditas fueron escépticos y vieron en las máquinas una racionalidad mecánica que no significaba progreso social sino todo lo contrario, al decir de David Noble (Noble, 1999). Como significación social del imaginario segundo, el progreso cumplió la función institucional de una ideología o justificación de la dominación, y en su función de temporalidad, hizo de utopía, colonizando las expectativas de cambio de una sociedad.

\section{La crisis del imaginario del progreso y la invención del desarrollo}

Es precisamente la literatura una de las fuentes donde se asienta lo imaginario. El siglo XIX, caracterizado por esa significación social de progreso, vio nacer los géneros utópicos caracterizados por un afecto de optimismo, desde las utopías sociales de Cabet, Fourier y Saint Simon hasta la ciencia ficción de Verne y Bellamy. En ellos, la ciencia y la técnica son elementos centrales de las maravillas que esperan en el futuro para la solución a las necesidades humanas. La asociación desarrollo técnico y progreso social es palpable. Llegado el siglo xx, hechos tan incontrovertibles como la explosión de la bomba nuclear en Hiroshima y Nagasaki pondrán de presente que el avance tecnológico no necesariamente significa progreso social, y se producirá una disociación de los dos términos en lo imaginario, lo que puede interpretarse como una crisis del progreso. Son los años 
de la gran crisis del 29, de la llegada de la Segunda Guerra Mundial, de los episodios de Auschwitz que luego se conocieron, y la detonación nuclear que muestra el poder destructivo de la tecnología nuclear. Las significaciones sociales no podían conservar el afecto optimista ni resultaba fácil direccionar las intenciones y deseos humanos. Aparece como prueba de ese quiebre en lo imaginario la literatura antiutópica o distópica, en obras que tienen en común lo absurdo e irracional de los avances tecnológicos, que muestran la pesadilla tras los sueńos embriagadores del progreso y el riesgo a que está expuesta la especie humana. Zamiatin, Huxley y Orwell muestran cómo las tecnologías han hecho posible el control, la vigilancia y la programación social. Ya no se trata de hacer realizables las utopías sino preguntarse, como lo hace Nicolás Berdiaeff en el epígrafe a Un mundo feliz de Huxley, cómo evitar su realización definitiva (Huxley, 2004, p. 5), Tras este escenario narrativo de perspectiva trágica, catástrofe y desencanto con la ciencia y la tecnología, se perfila la dificultad de la acción política en relación al destino deseado de la humanidad.

En esta crisis de la significación imaginaria del progreso se separan los sentidos de la técnica y la sociedad, los avances técnicos no conducen al progreso social y aparece la incertidumbre sobre el futuro y la desconfianza sobre la técnica. Ante esta crisis de lo imaginario, se insufla un nuevo vigor a los avances de la técnica, elemento central del capitalismo, recuperando la idea de la neutralidad, de que el problema reside en el uso que se hace de ella. Como lo expresa Cabrera, «(...) sucedió que la técnica fue 'redimida' a través del discurso del 'uso correcto' y así 'se salvó' la sociedad» (Cabrera, 2006, p.129, nota 41).

En la teoría social, el registro de esta crisis de las significaciones imaginarias del progreso se plasma en las tesis de la sociedad del riesgo (Beck, 1998), caracterizada por las consecuencias no previstas de decisiones. La vida moderna se caracteriza por padecer un nuevo tipo de riesgo, más allá de los riesgos naturales y de todos conocidos como las catástrofes naturales, se trata del riesgo manufacturado (Giddens, 2000) derivado de las consecuencias imprevistas del desarrollo tecnológico y observable en problemas como la contaminación, el cambio climático y el peligro nuclear, entre otros.

Vendrá la época de la tecnociencia y las innovaciones para la vida cotidiana, sobre las que se revivirá el afecto de optimismo perdido con el progreso. Es precisamente, tras los eventos de la Segunda Guerra Mundial y el episodio de Hiroshima, cuando el gobierno americano, en cabeza de Harry Truman, propone cambiar el término progreso por desarrollo, en la Asamblea de las Naciones Unidas de 1948 y el mensaje a la unión del año siguiente. Estados Unidos se comprometía a apoyar con su tecnología y conocimiento técnico a las zonas subdesarrolladas del mundo para que éstas pudiesen crecer y mejorar, lo que equivalía a entrar en la era del crecimiento de la producción, la introducción de tecnologías eficaces y el aumento del nivel de vida con referencia a la satisfacción de necesidades, la calidad de vida y el consumo propios de los países desa- 
rrollados. A este proceso se le denomina modernización y en ello está lo que Escobar ha denominado La invención del Tercer Mundo (Escobar, 1996).

Para incursionar en esta nueva búsqueda de la felicidad por la vía tecnológica, rápidamente comenzaron a circular manuales para orientar a los países y los encargados de las acciones, en donde se mostraba una escala de temporalidad diseñada para avanzar en el futuro hacia el desarrollo. Las etapas señaladas por Rostow iniciaban con el despegue hasta la etapa del consumo. En términos de lo imaginario, la idea de progreso había sido hábilmente reconvertida en una ola de modernización, un horizonte de expectativa para el mundo: «En este sentido, 'desarrollo' suponía una vuelta a la significación imaginaria del progreso, después de la pérdida de la inocencia tecnológica en la primera mitad del siglo XX». (Cabrera, 2006, p. 136)

Pero, pasada la década del sesenta, tras los cuestionamientos a la carrera tecnológica armamentista y las manifestaciones mundiales por la paz, y con la crisis del petróleo de comienzos de los setenta y el auge de los movimientos ecologistas, la idea de avance hacia el progreso presente en la significación imaginaria del desarrollo, sufría un nuevo resquebrajamiento.

\section{La globalización y la reinvención de lo imaginario del progreso}

De acuerdo con Cabrera, en los ochenta surgen las búsquedas en la cultura punk, la nueva era, el fin de las ideologías, el desencanto posmoderno y hasta el fin de la historia. Pero, asimismo, confluyen dos episodios, la caída del Muro de Berlín que significará la consolidación de la sociedad de mercado y se convertirá en pretexto para la ideología del globalismo; asimismo, el apogeo de las denominadas tecnologías digitales de información y comunicación, al igual que de las biotecnologías, aspectos que marcarán las significaciones imaginarias en los noventa y la nueva versión de un imaginario social segundo, que al sumergirse en el magma instituyente de la modernidad racional resurgirá con los destellos de una nueva utopía, la comunicación, y una nueva ideología, el tecnologismo.

De la comunicación como dimensión utópica, presente en la obra de Philipe Bretton (Bretton, 2000) y de la dimensión ideológica de la tecnología, retomada de las obras de Armand Mattelart (Mattelart, 2002) y Lucien Sfez (Sfez, 2005), Cabrera logra ubicar la expresión de las nuevas significaciones sociales imaginarias en los discursos dominantes de los noventa para acá sobre la tecnología y la comunicación, y que confluyen en lo que él denomina imaginario tecnocomunicacional. El origen de estas significaciones viene de mediados del siglo xx cuando aparecen la cibernética y la prospectiva, en las teorías de Wiener y Shanon, en las que se define la comunicación referida a posibilidad meramente técnica de transmisión de información de un punto a otro, dejando de lado los aspectos semánticos. Al aplicar el principio de entropía, según 
el cual existe una tendencia al caos y al desorden, la cibernética aparece como la ciencia del control, y a su vez, la información y la comunicación se convierten en las claves para luchar contra el desorden.

Los conceptos de información y comunicación se trasladan a todo lo pensable, se convierten en la metáfora heurística para pensar la realidad, empezando por la vida. Se empieza a hablar de la información registrada en los cromosomas, del código genético del ADN, de la biología molecular y de las biotecnologías, que llegarán al comienzo del siglo XXI a reconstruir el mapa del genoma humano. En estos discursos científicos de la información y la comunicación y su socialización, se empieza a gestar la matriz simbólica de un nuevo imaginario que descansa en la comunicación como clave para entender la realidad de la tecnología, de la vida, de la sociedad y del universo. A los elementos esenciales de esta matriz simbólica, Cabrera los denomina pancomunicación, tecnoinformación y análisis de futuro (Cabrera, 2006, pp. 138-148).

La idea de pancomunicación apunta a describir los discursos que se sustentan en la idea de comunicación: la idea de que todo es comunicación, todo se soluciona con comunicación, que hay que estar conectado, enchufado. Se habla de comunicación con fuerza de verdad en las significaciones imaginarias, esperando que se conviertan en verdades sociales. La idea de tecnoinformación describe los discursos que hacen de las tecnologías de información y comunicación el centro de la sociedad actual y buscan establecer lo deseable para los individuos y la sociedad, sustentada en la ideología del tecnologismo, y más concretamente de su versión informacional. El análisis del futuro apunta a construir escenarios futuros para controlarlos, en hacer del futuro un peligro calculable, para el que se diseñan técnicas y metodologías como la investigación de operaciones y modelación tipo Delfos. Es el campo de la prospectiva. Los escenarios futuros ideados por futurólogos y prospectivistas aciertan en las predicciones tecnológicas y fracasan en los pronósticos sobre los cambios sociales, pero de esa manera diseñan el futuro que se hará deseable y veraz de tanto repetirse por divulgadores al estilo de Alvin Toffler.

En la década de los noventa se gesta la nueva versión del imaginario del progreso, esta vez centrado en la comunicación y en la utopía de la sociedad de la información, como lo expresa Cabrera: «Este imaginario constituye el núcleo de la 'sociedad de la información' y la matriz simbólica de las nuevas tecnologías» (Cabrera, 2006, p. 146).

Las funciones ideológicas y utópicas de este imaginario se descubren, como se ha advertido, en toda la producción reciente de la teoría social en la que se decodifican los discursos de las significaciones sociales de las nuevas tecnologías. Dichos discursos son diseñados y puestos a circular por un conjunto de actores como los creadores, los promotores y los divulgadores de las nuevas tecnologías y; como institucionalidad, en el sentido de Castoriadis, tienen la función de justificar y legitimar acciones, deformar la 
realidad y proponer otra a la que se busca integrar a toda la sociedad, aspectos propios de una ideología:

«El imaginario tecnocomunicacional es, en primer sentido, ideología, en tanto justifica el orden social a través de discursos-promesas que acompañan la 'aparición' o 'advenimiento' de los aparatos tecnológicos» — y por ubicarse en la dimensión de la temporalidad, al convertir las promesas en esperanzas de un futuro deseable, son utopías - «en tanto participa de las esperanzas de cambio de los actores sociales y tiene otra visión de la apropiación de los aparatos técnicos» (Cabrera, 2006, p. 138).

De esa manera, colonizan la imaginación radical con las imágenes y representaciones de las significaciones sociales del imaginario segundo instituido. En un nivel ideológico son creencias que justifican la ruta que toman los hechos y la sociedad, y en un nivel utópico son representaciones e imágenes de una sociedad diferente que trata de hacerse realidad deseable. Estas dimensiones ideológica y utópica corresponden a estudios ya realizados de las nuevas tecnologías como los mencionados, con base en los trabajos clásicos de ideología y utopía de Karl Manheim (Manheim, 1993) y Paul Ricoeur (Ricouer, 1994). Sin embargo, el trabajo de Cabrera intenta ir más allá de decodificar la dimensión ideológica y utópica de las nuevas tecnologías como funciones de un imaginario tecnocomunicacional: «De ahí que sostengo que las nuevas tecnologías de comunicación son algo más o algo distinto que una utopía y una ideología. Son ellas mismas imaginario social instituido e instituyente de la sociedad contemporánea» (Cabrera, 2006, p. 148).

\section{Las nuevas tecnologías como significaciones sociales imaginarias y el imaginario neotecnológico}

La investigación empírica de Cabrera sobre lo imaginario en las nuevas tecnologías se centra en el análisis de los discursos de dos tipos de actores sociales, los promotores y los divulgadores, básicamente los discursos de los medios de comunicación y el marketing, por su papel en la producción de la realidad social y debido a que allí se encuentran las representaciones que dan estructura a las creencias sobre las «nuevas tecnologías». Tomando a 1994 como ańo de referencia de la generalización comercial del uso de Internet y 2001 como ańo de la caída del auge de Internet, retoma una muestra de textos publicados en español entre esas dos fechas, con algunas publicaciones analíticas surgidas hasta 2004.

En su estudio parte de considerar las «nuevas tecnologías» en su condición de tecnociencia como rasgo distintivo: «(...) el hecho de ser un producto de mercado, financiado y gestionado por empresas privadas donde el marketing y la publicidad son 
elementos esenciales» (Cabrera, 2006, p. 161). Asimismo, las define como un conjunto heterogéneo de aparatos, instituciones y discursos que, de acuerdo con sus indagaciones, constituyen el núcleo del imaginario tecnocomunicacional contemporáneo.

De tal definición, se desprende que tales elementos ocupan un lugar central en las representaciones de la realidad y el mundo, y sobre todo, en los sueños, esperanzas y deseos de la sociedad actual. Para la interpretación de los discursos, aclara el autor, el análisis consiste en sumergirlos en el magma para hacer resurgir los nuevos sentidos y desnudar la discontinuidad, la incoherencia y la heterogeneidad de lo que aparece como homogéneo, continuo y coherente en las significaciones sociales de las «nuevas tecnologías", lo mismo que el imaginario develado con la interpretación no solo aparece como un conjunto heterogéneo sino conflictivo entre visiones y representaciones de la realidad.

En los discursos sobre las «nuevas tecnologías» todo parece coherente y evidente cuando en verdad son conjuntos heterogéneos de fragmentos que se han hecho indiferenciados por el cemento del imaginario segundo instituido. El conjunto de aparatos es heterogéneo dado que une diferentes técnicas como las de nuevos materiales (silicio) con los artefactos de las tecnologías de información y comunicación, que vinculan la microelectrónica, las telecomunicaciones y la informática, y se emparentan con las biotecnologías. El nexo que las une es convergencia de lo digital. El conjunto de instituciones es igualmente heterogéneo puesto que involucra la ciencia, el mercado, la gestión y la innovación, y lo que las une es la tecnociencia y la gestión del conocimiento. A su vez, los discursos, provenientes de diferentes actores relacionados con dichas tecnologías, comprenden la publicidad, la producción editorial del know how, los informes públicos de políticos, las modas empresariales y las versiones de lo que hacen con ella los usuarios (Mattelart, 2002).

Este conjunto de fragmentos aparece cohesionado no sólo por razones de funcionalidad, lo que sería su heterogeneidad externa, sino porque constituyen las partes de un todo en razón de su institución social como socializadoras y como polo de identificación colectiva. Así, constituyen una matriz de representaciones, de designación de finalidades de la acción y establecimiento de afectos, constituyendo verdaderos tipos antropológicos (Cabrera, 2006, p. 160). A esta heterogeneidad que Cabrera denomina radical, en la medida en que ese conjunto hace parte de lo instituido por una sociedad, es decir, son lo que son porque condensan significaciones imaginarias centrales para la sociedad. Esas significaciones sociales que hacen parte de la sociedad tienen su núcleo en la matriz imaginaria de la modernidad, o sea, la racionalidad instrumental de dominio y la temporalidad como progreso. En otras palabras, encarna valores racionales, pero la heterogeneidad radical apunta a desnudar lo que aparece como racional, un fondo oscuro no develado. 
En el mismo nombre, «nuevas tecnologías», estas parecen tener la capacidad simbólica de aparecer siempre como nuevas. La verdad de su eficacia está probada y sin duda, como afirmara Castells (Castells, 2000), no se puede menospreciar su significado, pero Cabrera insiste en que no solo se trata de eso: «Sin embargo, lo decisivo del presente análisis no es la verdad o la falsedad ontológica de los acontecimientos sino su funcionamiento significativo social y, por lo tanto, su verdad pragmática» (Cabrera, 2006, p. 165). Se trata entonces, de preguntar por el funcionamiento discursivo, empezando por el nombre vacío en el que caben diferentes realidades, y que se usa en los discursos como sujeto u objeto en expresiones que muestran cómo las nuevas tecnologías cambiarán la sociedad o cómo cambiarán la vida de las personas, o como los sucesos futuros apuntan a un objeto, las nuevas tecnologías. Asimismo, en su calificativo de nuevas, siempre reinventándose en la innovación, haciendo de lo nuevo un valor incuestionable y sinónimo de bueno.

Las «nuevas tecnologías» impulsan a pensar la temporalidad como futuro y no como pasado. Configuran una nueva temporalidad social en la medida en que la dimensión temporal es vista con significaciones retomadas de las características de los artefactos y los sistemas tecnológicos. La inmediatez de las comunicaciones pone de presente el valor de la instantaneidad por encima de la capacidad de espera, y la velocidad de la información lanza a la aceleración de la vida y el ritmo de los procesos, como un dispositivo de control (Chávarro, 2008, p. 19), de anulación del futuro y trivialización del presente puesto que con la velocidad, el futuro ya está aquí:

Las «nuevas tecnologías» como futuro son posibilidades, pero como «están aquí» son reales. La promesa tecnológica y el optimismo que le es consustancial se convierten entonces en afectos dominantes. Las "nuevas tecnologías» como totalidad significativa imaginaria constituyen fuentes de futuro realizable que cabe esperar. El optimismo, la confianza y la espera son posibles. Ella cumplirá (Cabrera, 2006, p. 175).

La estructura del análisis del imaginario de las nuevas tecnologías o imaginario neotecnológico se sintetiza al postular matrices imaginarias con base en los polos de los ejes de temporalidad e institucionalización. En relación con el eje de temporalidad aparecen las representaciones de las nuevas tecnologías como promesa futura, advenimiento, destino inevitable y banalización del presente.

Respecto al futuro como promesa, los discursos del marketing estimulan la imaginación en aras de que las nuevas tecnologías se conviertan en productos indispensables, buscando establecerse como creencia a través de la fe en las marcas y mediante la retórica de la promesa autocumplida: «La promesa tecnológica conlleva la pretensión de un dominio sobre el curso de los acontecimientos futuros y esto es posible porque el futuro es convertido en presente: el futuro ya está aquí» (Cabrera, 2006, p. 179). La 
colonización de la imaginación se da porque al identificar nuevas tecnologías y futuro se actualiza la representación en relación con el imaginario moderno del progreso.

La promesa se convierte en afecto optimista con la idea de advenimiento, el anuncio de un acontecimiento necesario imparable. Aquí, las nuevas tecnologías se convierten en objeto y sujeto de las promesas, ellas vienen del futuro a la sociedad presente como si fuesen sujetos con voluntad propia y su presencia permite imaginar tiempos mejores, lo que da credibilidad a la promesa y hace olvidable todo hecho que la niegue. (Cabrera, 2006, p. 179)

El advenimiento, a su vez, se convierte en destino inevitable, imposible de detener, por lo tanto predecible y sin incertidumbre, porque el futuro ya está aquí con las nuevas tecnologías. En ese sentido, el presente resulta banalizado dado que es solo un lugar de realización de las promesas mediante la compra y el consumo de las nuevas tecnologías, y no como un lugar de acción. El presente es el escenario del consumismo y el vacío posmoderno, el repliegue en lo privado y la crisis de lo público. La expectativa del advenimiento, el anhelo consumista y el optimismo tecnológico muestran cómo se crea el futuro como horizonte de expectativa con las nuevas tecnologías.

Ya en relación con el eje de la institucionalidad, aparecen los afectos o actitudes frente a las nuevas tecnologías como confianza y fe, la ideología del mercado y el establecimiento de lo deseable mediante el imperativo tecnológico. Cabrera advierte que el problema de la actitud implica definir el afecto que acompańa a las nuevas tecnologías, que no es otro que el optimismo derivado de un imparable advenimiento sobre el que la confianza y la fe cumplen un papel fundamental. Sin confianza en la tendencia tecnológica se caería el sistema (Cabrera, 2006, p. 192) y la confianza en algo tan opaco como las nuevas tecnologías se convierte en fe, la fe ciega en las marcas y en los empresarios como gurús.

La ideología del mercado presente en el eje de institucionalización de las nuevas tecnologías proviene de la tecnociencia, esa consideración de la ciencia como factoría científica del modelo del taller de invenciones que hace vendible la técnica como en la famosa metáfora del garaje. Es una ciencia al servicio de lo empresarial y comercial encaminada a producir bienes de consumo bajo la lógica de la mercadotecnia o el marketing. Esta lógica se convierte en ideología al crear necesidades de estados de privación y moldearlas para convertirlas en deseos que motiven a la acción, estableciendo qué es lo imaginable y deseable.

El imperativo tecnológico alude a la apelación al cambio tecnológico como forma de reforzar la supremacía del mercado y la continuidad del orden social, es decir, en una versión mercantil de la historia que niega la política:

El imperativo tecnológico es en un sentido una "profecía que se cumple a sí misma»y, por ello, una versión del hado que como fuerza irresistible conduce a los seres humanos 
hacia un destino inevitable. O se acepta y hay posibilidades de adaptarse, o se la acepta y se es arrastrado por ella (Cabrera, 2006, p. 200).

En el cruce de los ejes de temporalidad e institucionalidad se descubre las formas de colonización de la imaginación por los discursos periodísticos, narrativos y publicitarios de las nuevas tecnologías en la temporalidad de lo nuevo y el don de la omnipotencia. Lo nuevo se impone desde la experiencia del usuario como la reducción del tiempo de trabajo y la liberación de la servidumbre de la repetición de labores, y desde lo publicitario como la evolución a corto plazo y el regreso de lo ya conocido, y el tiempo deviene en una transición permanente hacia lo más nuevo. Cabrera lo explicita de esta forma: "Las 'nuevas tecnologías' en tanto significación social imaginaria tienen una temporalidad donde la novedad proviene de la repetición» (Cabrera, 2006, p. 203), en otras palabras, un estado de novedad permanente resultado de la temporalidad cíclica del consumo y la moda, y la temporalidad lineal del progreso científico y tecnológico. Asimismo, las significaciones de las nuevas tecnologías acortan la distancia entre el espacio de experiencia y el horizonte de expectativas, es decir, se articula la experiencia cotidiana con los artefactos y la confianza en éstos como objetos de esperanza, y en ello el presente se convierte en lapso de espera y se enrarece como lugar de acción. Así, la creencia en un artefacto eficaz garantiza la bondad del futuro.

El otro cruce de los ejes de temporalidad e institucionalidad se muestra en la consideración de las nuevas tecnologías con un don de omnipotencia por un lado, y la facilidad de los usos, por otro lado. Los discursos publicitarios muestran la facilidad de los usos a la vez que se oculta su lógica, lo que genera una caracterización de artefactos omnipotentes o mágicos. De esta característica, el usar un artefacto sin comprender sus estructuras internas, Cabrera pasa a mostrar las matrices «irracionales» de las nuevas tecnologías:

Entre la complejidad de los saberes productivos y la simplificación de los saberes de uso, solo es posible el puente de la confianza y la colonización de la imaginación. La eficacia invisible de las «nuevas tecnologías» la convierte en magia, y a sus aparatos en maravillas dignas de admiración. (Cabrera, 2006, p. 214)

Así puede verse que lo imaginario de las nuevas tecnologías no responde a la lógica racional, explicable desde la ideología y la utopía del progreso, sino desde las búsquedas de la alquimia, fusión de magia y hermetismo por un lado y escatología por otro. La estimulación de la imaginación se da mediante promesas de los objetos técnicos a consumir: 
Todo esperar se despeja en la aparición del artefacto y, con él, la 'salvación' se realiza en el 'aquí y ahora' del consumo. Si desde la fe en el progreso la espera justificaba el sacrificio personal o generacional, desde los objetos neotecnológicos la espera culmina en el consumo inmediato y compulsivo de moda y novedad permanente. (Cabrera, 2006, p. 127)

Con esto, lo que muestra Cabrera es que el funcionamiento imaginario de las nuevas tecnologías no puede ser entendido sin las matrices mágica y escatológica en la articulación de la dimensiones de institución y temporalidad, y así se construyen la reglas de posibilidad desde las cuales se instituyen los sentidos de lo pensable, imaginable y deseable. Las nuevas tecnologías se han convertido en hecho social, dado que los discursos se refieren a los artefactos, pero los sentidos dados a estos se refieren a la sociedad.

\section{Lo imaginario de Internet}

En una formidable investigación empírica, Patrice Flichy estudia lo imaginario de Internet en los discursos de los creadores y promotores de Internet descubiertos en tres tipos de textos: boletines de especialistas en informática, textos universitarios y artículos de prensa tomados de cuatro publicaciones, una de ellas (Wired) especializada en el tema y que sirve como hilo conductor de la investigación, y tres revistas americanas (Time, Newsweek y Business Week), estudiadas de formas sistemática de 1991 a 1995.

Su enfoque teórico de lo imaginario se basa en los trabajos de Paul Ricoeur (Ricoeur, 1994) sobre utopía e ideología, y la noción de mito en Roland Barthes (Barthes, 2012). De acuerdo con las nociones de ideología y utopía de Ricoeur, Flichy parte de la tensión de lo imaginario social entre los polos de una tendencia a la estabilidad y conservación del orden social (la ideología), y la tendencia al cambio y transformación del orden social (la utopía) (Flichy, 2003, 18). De dicha tensión rescata los tres niveles presentados por Ricoeur: el primero, cuando la ideología es distorsión de lo real y la utopía una fantasmagoría irrealizable; el segundo, cuando la ideología se convierte en justificación o legitimación y la utopía en alternativa a lo existente; y el tercer nivel, cuando la ideología sirve para preservar la identidad del grupo y la utopía para explorar lo posible. Con base en estos niveles establece la estructura de la investigación para abordar lo imaginario técnico en tres fases, correspondientes a lo desencadenado por la tensión de esos niveles; la aparición de la utopía de las telecomunicaciones, la aparición del mito de Internet, y la aparición de la ideología del sistema técnico.

Lo imaginario de los creadores y promotores de Internet comienza a aparecer al estudiar el caso de las autopistas de la información, una utopía que no trasciende a mito sino a ideología-máscara. Las autopistas de la información se entienden como un 
proyecto de telecomunicaciones de fibra óptica que haría posible la televisión interactiva y la convergencia tecnológica. Con antecedentes en ideas de personajes de los ańos setenta, que se referían a las ciudades cableadas, hasta los proyectos de Albert Gore en los ochenta, Flichy logra mostrar cómo se construye una utopía de la comunicación que logra movilizar actores privados y políticos diversos que, aunque comparten una visión de mundo, no llegan a establecer acuerdos claros sobre el desarrollo del proyecto. El término autopistas de la información es entendido como una metáfora para nombrar un sistema técnico que se quiere vender como una revolución de la información y que debe difundirse a toda la sociedad. Flichy lo denomina, de acuerdo a una sociología de las innovaciones, objeto maleta dado que en él cabe un conjunto de dispositivos técnicos y proyectos sociales que logran movilizar actores del Estado y la sociedad civil hasta lograr obtener fondos públicos, pero que no logra consenso entre ellos: «Detrás de una utopía ampliamente compartida, los proyectos de los diferentes actores eran tan antagónicos que no se pudo realizar el consenso más que en cuanto a un programa mínimo[...]». (Flichy, 2003, p. 40)

La transformación de esta utopía en ideología-máscara logra impulsar un proyecto de liberalización de las telecomunicaciones, que luego se traducirá en la famosa desreglamentación o desregulación, que será clave para el desarrollo de todos los sistemas de telecomunicaciones en la llamada globalización. Este caso de las autopistas de la información, aunque no trasciende, logra anclar en lo imaginario social la utopía de la comunicación y la ideología de la libertad de las telecomunicaciones. Estos elementos serán centrales en los discursos posteriores como el de la sociedad de la información, mostrando con ello, cómo la realidad termina siendo modificada por las significaciones imaginarias de las nuevas tecnologías.

Respecto a Internet, la situación es diferente. Internet, la red de redes, es un dispositivo que se desarrolla en unos 20 años (de 1969-1989) en el marco de ambientes específicos como la investigación informática, la comunidad académica y algunos medios contraculturales y comunitarios, lo que evidencia un marco de innovación no mercantil, con la ventaja de que los usuarios son los mismos creadores. La imaginación de personajes como Joseph Licklider y Douglas Engelbart aportan mucho a la utopía con que nace este proyecto, en la idea de la simbiosis hombre-ordenador para trabajar en investigaciones de tiempo compartido, con formas colaborativas y así, acrecentar la inteligencia humana. Luego vendrá la idea de pensamiento asociativo, clave para el sueño de Vannevar Bush y Ted Nelson con el Proyecto Xanadú sobre el hipertexto, un nombre retomado del poeta Coleridge quien lo definía como el lugar mágico donde jamás se olvida nada. (Flichy, 2003, pp. 86-87)

Los antepasados de Internet son la red Arpanet, ligada al uso militar y estatal desde su creación en los sesenta; Usenet, la red académica de finales de los setenta, junto a otras redes científicas como Theorynet, Csnet, Bitnet y Nsfnet de comienzos de los 
ochenta. La red Internet empieza en los ochenta a aglutinar redes diferentes con un protocolo común. Hacia 1990 Tim Berners-Lee establece los vínculos en la información y se desarrolla la documentación hipertextual permitiendo navegar de un vínculo a otro, por lo que la denomina tela de arańa o web.

La razón del éxito de esta utopía reside, de acuerdo con Flichy, en el equilibrio entre el imaginario técnico y los usos, ya que los creadores eran los mismos usuarios. Esto hace pensar en la importancia de los referentes sociales en un sistema técnico. En este caso fueron el trabajo de colaboración entre colegas, el debate entre pares, y el hecho de constituir una comunidad apartada del resto de la sociedad. En esta idea de comunidad se asienta la utopía de las comunidades virtuales. El nuevo medio técnico de la red informática da lugar a la convergencia de tendencias contraculturales como los hippies del lema de amor y paz californianos, los hackers, técnicos chiflados por la informática que ven en la nueva comunicación el avance de las libertades, lo mismo que los aficionados, quienes quieren imitar a los universitarios, y todo un movimiento de desarrollo comunitario que valora lo local. La conversión en mito de esta utopía de comunidades informáticas se dará en la obra de un periodista, Howard Rheingold.

Pero la comercialización y universalización de la red crea una distancia entre la utopía inicial de los creadores y su realización dado que lo universal va difuminando lo local y los usuarios se vuelven heterogéneos, debido a que éstos ya no son creadores sino receptores. Sin embargo, el imaginario inicial no se modifica. Se sigue promocionando lo virtual como el mundo de lo igualitario que permite el acceso universal: «La utopía se convierte en este caso en ideología que encubre la realidad, pero que al mismo tiempo, moviliza actores». (Flichy, 2003, p. 120)

Pero para consolidarse como ideología se debe crear bien el mito fundador, y es así como Internet aparece en la agenda mediática. Rheingold, con el libro ya mencionado, publicado en 1993, considerado el libro del año por Business Week, afirma, haciendo verdadera epopeya de algunas comunidades virtuales como Well, que la Red aparece como la posibilidad de intercambio entre iguales, de consolidación de un nuevo espacio público, y que, por ello, será dinamizadora de la democracia. En virtud de esta idea, Rheingold es considerado el primer netciudadano. Sin embargo, la realidad dista de ser así. A partir de su socialización, los usuarios de la Red serán cada vez más diferentes de los creadores y emisores de mensajes, por lo que perderán la pregonada autonomía de este sistema técnico.

Como ideología, la nueva tecnología requiere de un imaginario de masas que movilice actores en pro de Internet centrado en el mito de lo comunitario y libertario. Las luchas simbólicas por imponer esta ideología se pueden percibir, al detalle, en las publicaciones que analiza Flichy. Algunas de estas publicaciones como los manuales de Internet, comienzan a aparecer masivamente hacia 1992, y en ellos se descubren representaciones que ligan el cambio tecnológico con el cambio social. En Zen and Art 
of Internet se lee "Estamos verdaderamente en una sociedad de la información" (Cit. Flichy, 2003, p. 125). Otro manual, Whole Internet de Ed Krol, logra vender ese año 750.000 ejemplares. En Internet Started aparece «En nuestra era, información es poder» (Flichy, 2003, p. 125), y así, una profusión de calificativos de cambios sociales venideros atribuidos a Internet.

Otro género es la prensa, que reacciona asociando la Red a la anarquía, la contracultura hippy, la piratería y la pornografía. A esto responde el género de revistas de vulgarización para aficionados a la Red, como Internet World, que la imagen que da la prensa de Internet es sesgada. Otra revista, Net Guide, se convierte en pionera al mostrar las posibilidades de Internet en el uso del tiempo libre (Flichy, 2003, pp. 128-129). Obviamente, tras la comercialización generalizada del nuevo sistema técnico, la prensa modificará sus puntos de vista, y la distancia crítica sólo será para algunos columnistas.

Otro aspecto proveniente de la utopía precedente es la netiqueta. Las normas sociales del nuevo medio, que ya se habían creado con Usenet hacia 1985, se refieren a lo necesario para el saber vivir electrónico y consisten en un código caballeresco que constituye el tiquete de entrada (ticket) al nuevo medio, contribuyendo con ello a crear las convenciones simbólicas de la comunidad de usuarios. Todo esto ayudará a reafirmar la idea de que el modelo universitario podía ser aplicado en el mundo ordinario y que el internauta puede disfrutar de relaciones igualitarias e información gratuita, en fin, deslizando la utopía en la ideología, a lo que comenta Flichy: «Estos discursos tienen, por tanto, un fuerte componente embaucador, y están en la base de esta ideología de Internet que seduce, moviliza y oculta el funcionamiento real de la nueva tecnología» (Flichy, 2003, p. 184). Y efectivamente, con el uso generalizado de Internet, luego de 1994, comienzan a aparecer desigualdades de acceso y capacidades en torno a la red entre los usuarios creadores y los no productores ni emisores, y además, con los no usuarios.

Si bien se logra percibir el imaginario naciente en múltiples fuentes, Flichy nos hace detener en un medio específico. La publicación donde se gesta el imaginario de las nuevas tecnologías y de Internet en particular es Wired, la ciberrevista, asociada al Media Lab del Instituto Tecnológico de Massachussets (MIT). En sus páginas se crea la idea de revolución informática y cambio social. Uno de sus directores, Louis Rossetto afirma: «(...) la revolución numérica transforma nuestras vidas como un tifón de Bengala» (Flichy, 2003, p. 135). En otra afirmación, la compara con la invención del fuego. El otro director, Jabe Metcafe, habla de mutación fundamental. La revista agrupa a colaboradores como Howard Rheingold, Nicholas Negroponte, algunos miembros de las comunidades virtuales, futurólogos como Alvin Toffler, novelistas ciberpunk como William Gibson, introductor del término ciberespacio, Bruce Sterling y otros, además de los prospectivistas y partidarios de la nueva economía, en fin, toda una ciberélite de 
la generación digital, por la que serán llamados los digerati (Flichy, 2003, pp.135-137). En esta tribuna de la revolución digital los artículos se presentan como anuncios, con eslogan y fotos retocadas, retomando el lugar que tiene la imagen en la web. Su circulación crece al ritmo de 100000 lectores cada ańo, en los noventa. Rápidamente atrae los clubes de expertos en reflexión y prospectiva que sirven de mediadores con el mundo empresarial, entre ellos el economista Michel Porter, Thomás Malone, Francisco Varela, la socióloga Sherry Turkle, Steward Brand, exhippy y autoconsiderado experto en fabricación de utopías (Flichy, 2003, p. 140), entre otros. Esta ciberélite se adjudica el cargo de fabricar lo imaginario de Internet presentando las nuevas formas de la sociedad, la economía, la política y la cultura con el suceso de la revolución digital. Hacia 1995 se declara el año de Internet. News Week en su portada coloca "Esto cambia...todo». (Flichy, 2003, p. 141)

Como ya se ha mostrado en otra parte, el estudio de los discursos publicados en Wired tiene el valor de una antología de los creadores de lo imaginario del mundo digital. Los llamados gurús como Nicholas Negroponte, los futurólogos como Alvin Toffler o George Gilder, los prospectivistas, etc., construyen unas representaciones de cambio que puestas a circular en los procesos de vulgarización darán forma a lo imaginario de las nuevas tecnologías y en particular, de Internet. Para dar fondo a su proyecto, crean un dúo de santos patronos, profetas o visionarios como Teilhard de Chardin y Marshall McLuhan. En 1980, el año de la muerte de McLuhan, se publica La tercera ola de Toffler, que no es otra que la ola de la información, y que convierte las ideas de Chardin y McLuhan en un relato coherente de determinación tecnológica de la sociedad. A partir de este hecho, las ideas para referirse a los medios técnicos anteriores serán las de los mediasaurios, como los denominará el escritor Michel Crichton (Cit. Flichy, 2003, p. 155). En estos discursos las características de la nueva era son la desmasificación, la convergencia tecnológica, el consumo diversificado. Peter Drucker habla de prosumidor, de organizaciones basadas en el trabajo colaborativo digital colocando la metáfora de la orquesta de jazz. El heredero de McLuhan, Derrick de Kerkhove, habla de que lo pequeño es poderoso, los medios de producción están en manos de los trabajadores, los usuarios de la Red. Con estas megatendencias, se crea la opinión favorable a la disminución del Estado, a una descentralización que permitirá el resurgir de las regiones, a mayor participación dado que las nuevas tecnologías permiten la participación directa en los asuntos públicos, a la caída de las jerarquías debido a que los individuos se orientarán a sí mismos, a la proliferación de ciberleyes globales, a la circulación liviana del conocimiento liberándonos de los átomos.

Entre los productores de discursos que agrupa la revista se encuentran artistas que ven en la tecnología la posibilidad de nuevas formas de imaginación como lo virtual. Novelistas y artistas de la corriente ciberpunk, la música tecno y otras corrientes coinciden con informáticos y exhippies en dar un lugar central en la confección de lo ima- 
ginario a lo virtual. Parten de no copiar lo real sino imaginar una nueva realidad que la tecnología puede hacer experimentable y vivida como si fuese real, mediante la estimulación de ciertos sentidos y con dispositivos que para ello se diseñan, resultando de ello la simulación, propia de la realidad virtual, un medio subjetivo que produce sensación de realidad. Esta chispa tecnológica dispara la imaginación en el medio informático y se llega a creer que la informática es el verdadero lugar de la vida y a justificar liberarse del cuerpo en la Red, desconectarse de lo corporal y leer el espíritu, o tener sexo sin riesgos ni implicaciones reales. Algunos informáticos llegan a imaginar que algún día se pueda cargar la mente en el ordenador y lograr la inmortalidad. Por otro lado, una corriente de estos tecnólogos se centra en la inteligencia artificial, una forma de poder construir máquinas inteligentes que puedan suplantar a los humanos. En varias de las novelas de la corriente ciberpunk, en el futuro las máquinas dominan a los hombres. Con todo esto, se crea una utopía de la realidad virtual, los cyborgs o individuos capaces de regularse en un medio ambiente artificial.

En todo esto se ve cómo el mito y el instrumento, de acuerdo con Flichy, se constituyen mutuamente. El elemento utópico moviliza y coloniza la imaginación de los usuarios, fascinados con la simulación y las posibilidades de la realidad virtual, y el elemento ideológico justifica el aislamiento de lo social y el repliegue en sí mismo haciendo creer que se puede manipular el mundo desde el ordenador:

Pero lo imaginario de lo virtual se convierte en ideología cuando imagina que se puede poner el propio cuerpo entre paréntesis, que la informática permite crear relaciones humanas acorporales, desconectadas de todo compromiso del cuerpo en el espacio y en la duración, que se pueden desarrollar relaciones humanas que no sean otra cosa que enriquecimiento y placer, eliminando toda soledad y dolor. (Flichy, 2003, p. 204)

Otra forma de relacionar el señuelo utópico con el anzuelo ideológico radica en los discursos de los digerati sobre el fin de lo político y del Estado. En las publicaciones de Toffler, Gilder y Rheingold se puede descubrir la asociación de las nuevas tecnologías y de Internet en particular con una democracia directa, desde las posibilidades de voto por ordenador hasta las comunicaciones directas de los ciudadanos con los gobernantes y los experimentos de participación de las redes ciudadanas y las comunidades virtuales. El debate sobre la utopía de los usos políticos de la Web ya se ha presentado en otro lugar (Chávarro, 2008, p. 81), pero lo que aquí interesa destacar, de acuerdo con Flichy, es el trasfondo ideológico. Las referencias de Internet como el ágora pública se pueden poner a prueba con lo que Mark Poster denomina características de un espacio público: el debate entre iguales, la prevalencia de argumentos racionales y la búsqueda de consenso. Flichy muestra que Internet solo podría pasar la primera prueba, suponiendo que los usuarios de verdad se comportasen como 
iguales. Las famosas comunidades en línea tienen todo menos grandes compromisos, las identidades de sus miembros suelen ser móviles, muchos opinan amparados en el pseudónimo y buscando defender puntos de vista que ya se tienen, no en aras de lograr consensos, por lo que más bien aparecen sujetos con posiciones de rigidez y no de flexibilidad. Una forma sencilla de descubrirlo es mirando los blogs, o también en los comentarios a los artículos de opinión de la prensa. Creer que un medio técnico vuelve a la gente demócrata no es más que determinismo tecnológico: «Espíritus informáticos puros no pueden crear una democracia deliberativa. En este sentido, Internet no es un nuevo espacio público, no es un lugar que pueda permitir vivificar de nuevo el debate democrático». (Flichy, 2003, p. 211)

Con esta premisa tecnológica, los digerati construyen el modelo para una sociedad sin Estado, una verdadera contradicción de los términos porque hablar de democracia sin Estado es un verdadero sofisma que más bien significa una ideología-máscara. Crear un mundo sin intervención del Estado es un ideal libertarista, mezcla de liberalismo económico y anarquismo empresarial, puesto que como ya se ha mostrado con las autopistas de la información, sirve para afianzar la creencia en que la desreglamentación de las telecomunicaciones es fundamental para el desarrollo del nuevo medio, y por ende, para libertad de empresa. Hoy se puede constatar el fenómeno de la concentración mediática e informática, en el que unos pocos productores y proveedores monopolizan el mercado de la comunicación y la información, lo que sí es un verdadero problema para la democracia que se sustenta en la libertad de opinión. El sostener que un medio tecnológico debe mantenerse sin regulación estatal equivale a ver en el Estado el peligro a la intimidad cuando en realidad son las grandes compañías las que amenazan la democracia con procedimientos como la desreglamentación y la privatización, que vaya coincidencia son postulados centrales en el Consenso de Washington. La fusión de la utopía hippie californiana y la ideología yuppie de Silicon Valley tiene una fórmula para colonizar la imaginación: determinismo tecnológico más liberalismo económico (Flichy, 2003, 222). Una muestra de ello está en la oposición de los digerati de Wired a la censura a la pornografía y al control de los contenidos, expuesta en el proyecto de ley sobre la decencia en las comunicaciones, la Communication Decenty Act propuesta en el Congreso de Estados Unidos, y que convertida en ley, fue demandada por los libertarios de Wired. (Flichy, 2003, pp. 231-232)

En el mismo sentido, a pesar de los intentos de mantener el acceso público a los bienes informáticos como los movimientos de software libre de los creadores de Unix y Linux, la comercialización y el marketing, postulados de los futurólogos de Wired, fue ganando terreno hasta convertir a lo digital en elemento central de una nueva economía inmaterial. Todo tipo de metáforas sobre el trabajo en la Red fueron surgiendo y dieron lugar a los discursos pilares del llamado neoliberalismo de los noventa: la descentralización, el outsourcing, la desregulación, globalización de los negocios, revolución 
informática y, por supuesto, la libertad de empresa de la privatización, todo ello cuando el Estado ya había puesto los fondos públicos para que el nuevo sistema tecnológico pudiera ser realidad:

[...] precisamente, la fuerza de este discurso consiste en afirmar que Internet no puede funcionar más que en una economía neoliberal y que las tecnologías informáticas de red comportan un nuevo modo de funcionamiento de los mercados financieros, una nueva organización de las empresas, relaciones directas entre vendedores y compradores, nuevos modos de acceso al saber. (Flichy, 2003, p. 263)

Como se ha visto, la investigación de Flichy sobre lo imaginario de Internet muestra las oscilaciones entre el polo de la utopía fundadora, luego traicionada por los intereses comerciales y convertida en utopía señuelo para la difusión del nuevo sistema tecnológico, y el polo de la ideología del liberalismo económico, que encuentra en el mundo digital una forma de producir sus discursos y sus metáforas, y así justificarse y legitimar un tipo de sociedad de mercado sin intervención del Estado y una visión de futuro que genera identidad, como reencauchamiento del imaginario del progreso, en el sentido en que, como se ha visto al comienzo de este trabajo, lo ha mostrado igualmente Daniel H. Cabrera. Pero un descubrimiento interesante en el trabajo de Flichy radica en mostrar cómo el imaginario de Internet se nutre de representaciones del pasado histórico de la sociedad donde surge, Estados Unidos. Retomando la obra clásica de Alexis de Tocqueville, descubre que representaciones propiamente americanas como las nociones de frontera, comunidad e iniciativa individual se actualizan en lo imaginario de Internet en las ideas de la utopía de los fundadores y descubridores de un espacio virgen en el que pueden poner sus propias reglas de vida comunitaria y en el que los hombres se hacen a sí mismos con sus iniciativas empresariales, manteniendo lejos las instituciones del Estado. En fin, el origen de este imaginario en representaciones típicamente americanas también tiene sus consecuencias culturales en el imperialismo de la lengua inglesa, la lengua de sus creadores.

Lo imaginario implica construir las formas de ver la realidad, y la realidad depende de lo que los usuarios realmente hacen en la Red. Pero lo que hacen, lo hacen a través de los filtros de la utopía y de lo que se considera pensable o imaginable. Esto invita a revisar las implicaciones de lo imaginario en las prácticas sociales: «Lo imaginario está en el centro de la concepción y de los usos de Internet. Como observaba ya Michel de Certeau, 'las narraciones marchan por delante de las prácticas sociales para abrirles el camino'». (De Certeau, citado en Flichy, 2003, p. 269)

Para finalizar, son pocos los trabajos críticos con un calado conceptual sobre la noción de lo imaginario como los comentados aquí sobre las nuevas tecnología e internet, por lo que su conocimiento y discusión se imponen como una forma de 
orientar reflexiones en un siglo xxI que ya no puede prescindir ni de las nuevas tecnologías digitales ni de internet, pero que sí requiere de unos Estados con la fortaleza suficiente para albergar la democracia que pueda gestarse en estas nuevas formas del ágora y la esfera pública, que por ahora parecen más bien parecen impulsar al individualismo conectado y la reducción del diálogo civilizado a la opinión gregaria de las llamadas redes sociales.

\section{Referencias}

Attali, J. (1982). Historias del tiempo. México: FCE.

Barthes, R. (2012). Mitologías. Madrid: Siglo XXI.

Beck, U. (1998). La sociedad del riesgo. Hacia una nueva modernidad. Barcelona: Paidós.

Bretton, P. (2000). La utopía de la comunicación. Buenos Aires: Nueva Visión.

Cabrera, D. H. (2006). Lo tecnológico y lo imaginario. Las nuevas tecnologías como creencias y esperanzas colectivas. Buenos Aires: Biblos.

Carretero, A. (2003). La radicalidad en lo imaginario de Cornelius Castoriadis. Revista Anthropos: Huellas del conocimiento, 95-105.

Carretero, A. (2004). La relevancia de lo imaginario en la cultura actual. En: Nómadas, Revista crítica de ciencias sociales y jurídicas. No 9.

Castells, M. (2000). La era de la información. La sociedad red. Madrid: Alianza.

Chávarro, L. (2008). Tecnología, sociedad e información. Cali: Universidad del Valle.

Durkheim, E. (2000). Representaciones individuales y representaciones colectivas. En: Sociología y filosofía. Madrid: Miño y Dávila, pp. 35-53.

Flichy, P. (2003). Lo imaginario de Internet. Madrid: Tecnos.

Giddens, A. (2000). Un mundo desbocado. Madrid: Taurus.

Habermas, J. (1980). La ciencia y la tecnología como ideología. En: Barnes, Barry (comp.) Estudios sobre sociología de la ciencia, Madrid: Alianza.

Huxley, A. (2004). Un mundo feliz. Bogotá: El Tiempo.

Le Goff, J. (1990). La nueva historia. En: Le Goff, Jacques. (Dir.) La nueva historia. Bilbao: Mensajero, pp. 263-298

Mannheim, K. (1993). Ideología y utopía. México: FCE.

Marcuse, H. (1985). El hombre unidimensional. Barcelona: Planeta-Agostini.

Mattelart, A. (2002). Historia de la sociedad de la información. Barcelona: Paidós.

Mumford, L. (1996). Técnica y civilización, Madrid: Alianza.

Nisbet, R. (2006). Historia de la idea de progreso. Madrid: Tecnos.

Noble, D. (1999). La religión de la tecnología. Barcelona: Paidós.

Ricoeur, P. (1994). Ideología y utopía. Barcelona: Gedisa.

Sfez, L. (2005). Técnica e ideología. México: Siglo XXI. 